\title{
Retailer's optimal policies for deteriorating items with a fixed lifetime under order-linked conditional trade credit
}

\author{
Nita H. Shaha*
}

${ }^{a}$ Department of Mathematics, Gujarat University, Ahmedabad - 380009, Gujarat, India

\begin{tabular}{l}
\hline C H R O N I C L E \\
\hline Article history: \\
Received July 2, 2016 \\
Received in revised format \\
September 10, 2016 \\
Accepted October 202016 \\
Available online \\
October 20 2016 \\
\hline Keywords: \\
Inventory \\
Price-sensitive demand \\
Credit financing \\
Deterioration \\
Fixed lifetime \\
\end{tabular}

\begin{abstract}
A B S T R A C T
The player uses credit financing to perform profitable business. We analyze an economic order quantity model in which items have a fixed lifetime and deteriorate over time. The supplier offers the retailer a full credit period whenever the retailer orders more than or equal to a prespecified quantity. If the retailer orders less than pre-specified order quantity, then the retailer will do partial payment to the supplier and avail of delay in payments for the remaining outstanding amount. The demand is price-sensitive. The retailer's profit is maximized by setting appropriate retail price and replenishment time. The algorithm is developed to choose the best policy for the decision maker from the number of alternatives. Numerical data is used to validate the theoretical developments. Managerial insights are discussed. It is observed that for a given units to qualify for avail of partial credit period, increase in ordering cost decreases profit of the retailer. The increase in rate of the purchase cost to avail of delay payment suggests that to have a more profit, retailer should deplete stock before the allowable credit period.
\end{abstract}

(C) 2017 Growing Science Ltd. All rights reserved.

\section{Introduction}

The promotional tool trade credit is used to enhance the demand and attract new customers for whom it is one type of discount. However, it involves risk for the supplier when longer credit period is offered as some of the retailers may not able to pay off dues. Goyal (1985) model discussed an economic order quantity model under permissible delay in payments. The interest earned and interest charged are computed on purchase cost. Shah (1993) studied the effect of deterioration in Goyal's model by calculating interest earned on selling price which is higher than the purchase cost. Jamal et al. (1997) incorporated shortages to minimize total cost per unit time of an inventory system. Hwang and Shinn (1997) analyzed the effect of credit period on purchase quantity under price-sensitive demand. Here, the selling price and cycle time are decision variables which maximize the total profit per unit time. Teng (2002) advocated decision maker for smaller orders to avail of credit period frequently. To attract the buyers, player uses promotion tool of credit period to those who order more than the specified quantity. Chang et al. (2013) analyzed a vendor - buyer supply chain under order-linked credit period to settle the account, demand dependent selling price and production rate proportional to the demand rate. Refer review articles by Chang et al. (2008), Shah et al. (2010) and Molamohamadi et al. (2014).

* Corresponding author

E-mail address: nitahshah@gmail.com (N. H. Shah)

C 2017 Growing Science Ltd. All rights reserved. doi: $10.5267 /$ j.uscm.2016.10.003 
Soni and Shah (2008) formulated inventory model for determining optimal order quantity when demand is stock - dependent. They considered a scenario of two successive credit periods for settling the account against the dues. Teng et al. (2011) generalized Sony and Shah (2008)'s model by assuming positive inventory at the end of the cycle time when inventory system is constrained with a floor space and items deteriorate exponentially. They discussed retailer's policies when the supplier offers a progressive permissible delay in payments. If player is not in a position to settle the account in due course of time then some credit period can be offered to him but interest rate is higher in this new offer. Shinn and Hwang (2003) analyzed retailer's inventory policies under order-quantity dependent credit period for price-sensitive demand. Ouyang et al. (2005) incorporated cash discount offer from seller and credit period to the retailer. They compared review policy of cash-on-discount with the proposed problem. Ouyang et al. (2006) discussed generalized inventory model for deteriorating items when partial backlogging is allowed. Goyal et al. (2007) studied the retailer's purchase strategies when two credit periods are offered progressively. Under progressive credit period scenario, the retailer was charged higher interest rate on the unpaid dues. Huang and Hsu (2008) assumed that the retailer passes credit period to the customers by relaxing relation between selling price and purchase cost, the rate of interest rates and the lengths of the allowable credit periods. Liao (2008) computed interest earned on selling price and interest charged on purchase cost (less than the selling price) to study the effect of credit period when replenishment rate is finite and units in inventory deteriorate at a constant rate. Chang et al. (2010) maximized the profit of the decision maker under floor-space constraint and with rampant inventory at the end of the cycle time. Kreng and Tan (2010) studied optimal policy under two levels credit period which are order dependent when system suffers imperfect production phase. Kreng and Tan (2011) discussed finite replenishment inventory model under two-level trade credit incorporating the scenarios of defective items and scrape items. Teng and Lou (2012) formulated inventory model when supplier's demand is credit dependent and retailer offers a fixed credit period to the customers. Cheng et al. (2012) computed threshold for retailer's payment time and cycle time under trade credit and other financial strategies.

Huang (2007) formulated an optimal order quantity under conditionally permissible delay in payments. In this scenario, the supplier offers the retailer a full permissible delay period if the retailer orders more than or equal to pre-specified quantity. If order is less than the pre-specified quantity, the retailer will pay partial payment from the total dues and remaining account is to be settled in the permissible credit period. Chen et al. (2014) revisited Huang's model and derived results using arithmetic-geometric method.

The present study extends Chen et al. (2014) model when demand is price-sensitive. The items have a fixed lifetime and subject to deterioration with time. The discussed model is more realistic. The profit per unit time of the retailer is maximized with respect to unit selling price and cycle time. Theoretical analysis is done for different alternatives. Finally, the model is validated using numerical data. Based on the output, managerial issues are listed.

\section{Notations and Assumptions}

We adopt the following notations to develop the proposed model with conditional trade credit for items of fixed lifetime and deterioration with time.

$R(P) \quad$ The price-sensitive annual demand rate (in units)

$A \quad$ The ordering cost per order (in $\$$ )

$C \quad$ The unit purchase cost (in $\$$ )

$P \quad$ The unit selling price (in $\$$ ) with $P \geq C$ (a decision variable)

$h \quad$ The holding cost per unit per annum excluding interest charges (in $\$$ )

$M \quad$ The credit period offered by the supplier (in years)

$I_{e} \quad$ The interest earned per $\$$ per year by the retailer 
$I_{c} \quad$ The interest to be paid by the retailer per $\$$ per annum with $I_{c} \geq I_{e}$

$\alpha \quad$ The fraction of the purchase cost for which delay in payments by the supplier is permitted

$m \quad$ The maximum lifetime of the product (in years)

$\theta(t) \quad$ The deterioration rate with $0<\theta(t)<1$

$Q_{d} \quad$ The pre-specified units by the supplier at which full credit period is permitted (in units)

$T_{d} \quad$ The time during which $Q_{d}$ - units are sold (in years)

$T \quad$ The retailer's replenishment time (in years)

$Q \quad$ The retailer's purchase quantity (in units)

$\pi(P, T) \quad$ The retailer's total profit per unit time (in $\$$ )

$P^{*} \quad$ The retailer's optimal selling price which maximizes the total profit per unit time (in \$)

$T^{*} \quad$ The retailer's optimal cycle time (in years)

$Q^{*} \quad$ The optimal purchase quantity (in units)

$\pi^{*} \quad$ The retailer's maximum total profit per unit time (in \$)

The proposed model is formulated using following assumptions.

1. The retailer stocks single item having expiration date of $m$-years.

2. The demand rate is price-sensitive with functional form $R(P)=a P^{-\eta}, a>0$ is scale demand, $P$ denotes selling price and $\eta>1$ is price-elasticity mark-up.

3. The replenishment rate is infinite.

4. The planning horizon is infinite.

5. The shortages are not allowed and lead-time is zero or negligible.

6. The items in retailer's inventory system deteriorate with rate $\theta(t)=\frac{1}{1+m-t}, T \leq m$. The deteriorated units are neither repaired nor replaced during the cycle time.

7. The retailer enjoys full credit period offered by the supplier if order is greater than or equal to the pre-specified quantity. Here, the retailer will pay total purchase cost $C Q$ at the end of the allowable credit period. If order quantity is less than the pre-specified quantity, then the retailer will do partial cash down payment of $(1-\alpha) C Q$ and remaining dues can be paid at the end of the credit period.

8. The retailer pays to the supplier an interest at the rate of $I_{c}$ on unpaid balance during $[M, T]$. During $[0, M]$, the retailer can incur an interest at the rate $I_{e}$ by depositing generated revenue in investment firm.

In the next section, we formulate the mathematical model for the retailer to set up optimal selling price and purchase quantity which maximize the profit.

\section{Mathematical Model}

The rate of change of inventory is due to customer's demand and deterioration of items. It is governed by the differential equation

$\frac{d I(t)}{d t}=-R(P)-\theta(t) I(t), 0 \leq t \leq T \leq m$ with $I(0)=Q$ and $I(T)=0$. 
Then $I(t)=a P^{-\eta}(1+m-t) \ln \left(\frac{1+m-t}{1+m-T}\right), 0 \leq t \leq T \leq m$ is the solution of the differential equation that denotes inventory level at any instant of time $t \in[0, T]$. The order quantity is $Q=I(0)=a P^{-\eta}(1+m) \ln \left(\frac{1+m}{1+m-T}\right)$.

The total profit $\pi(P, T)$ per unit time depends on the lengths of $M$ and $T_{d}$. We discuss two possible cases: (1) $T_{d} \leq M$, and (2) $T_{d}>M$.

\subsection{Case 1: $T_{d} \leq M$.}

The basic costs per unit time are

(a) Ordering cost, $O C=\frac{A}{T}$.

(b) Holding cost, $H C=\frac{h}{T} \int_{0}^{T} I(t) d t=\frac{h a P^{-\eta}}{4 T}\left[T^{2}-2 T(1+m)+2 \ln \left(\frac{1+m}{1+m-T}\right)(1+m)^{2}\right]$.

(c) Purchase cost, $P C=\frac{C Q}{T}=\frac{C a P^{-\eta}(1+m)}{T} \ln \left(\frac{1+m}{1+m-T}\right)$.

(d) Sales revenue, $S R=\frac{P}{T} \int_{0}^{T} R(P) d t=a P^{-\eta+1}$.

(e) For interest earned and interest paid, the three cases are to be discussed depending upon the lengths of $M, T$ and $T_{d}$.

Sub-case 1.1: $T_{d} \leq M<T$. The retailer has a liberty to enjoy full credit period because order quantity is greater than or equal to pre-specified order quantity. The interest earned on the generated revenue during $[0, M]$ is $I E_{1}=\frac{P I_{e}}{T} \int_{0}^{M} R(P) t d t=\frac{a P^{-\eta+1} I_{e} M^{2}}{2}$. During $[M, T]$, the retailer pays interest against unsold stock at the rate $I_{c}$ as

$$
\begin{aligned}
& I C_{1}=\frac{C I_{c}}{T} \int_{M}^{T} I(t) d t \\
& =\frac{C I_{c} a P^{-\eta}}{4 T}\left[T^{2}-M^{2}-2(T-M)(1+m)+2 \ln \left(\frac{1+m-M}{1+m-T}\right)\left((M-1)^{2}+m^{2}-2 M m+2 m\right] .\right.
\end{aligned}
$$

Sub-case 1.2: $T_{d} \leq T \leq M$. Here, also retailer receives full credit period to settle the account due against the purchases. Additionally, the cycle time is shorter than the allowable credit period. So, interest charged, $I C_{2}=0$ and interest earned on the generated revenue during $[0, M]$ is $I E_{2}=\frac{P I_{e}}{T}\left[\int_{0}^{T} R(P) t d t+R(P) T(M-T)\right]=a P^{-\eta+1} I_{e}\left(M-\frac{T}{2}\right)$.

Sub-case 1.3: $T<T_{d} \leq M$. The retailer orders less than the pre-specified order by the supplier. So, partial payment is to be made at the time of delivery. The interest paid, 
$I C_{3}=\frac{(1-\alpha) C I_{C}}{T} \int_{0}^{T} I(t) d t=\frac{(1-\alpha) C I_{c} a P^{-\eta}}{4 T}\left[T^{2}-2 T(1+m)+2 \ln \left(\frac{1+m}{1+m-T}\right)(1+m)^{2}\right] \quad$ and interest earned on the generated revenue, $I E_{3}=\frac{\alpha a I_{e} P^{-\eta+1}(2 M-T)}{2}$.

The total profits per unit time for the retailer in three sub-cases are

$$
\begin{aligned}
& \pi_{1}(P, T)=S R-P C-O C-H C+I E_{1}-I C_{1}, T_{d} \leq M<T \\
& \pi_{2}(P, T)=S R-P C-O C-H C+I E_{2}-I C_{2}, T_{d} \leq T \leq M \\
& \pi_{3}(P, T)=S R-P C-O C-H C+I E_{3}-I C_{3}, T<T_{d} \leq M
\end{aligned}
$$

Clearly, $\pi_{1}(P, M)=\pi_{2}(P, M)$ and for $\alpha=1, \pi_{2}\left(P, T_{d}\right)=\pi_{3}\left(P, T_{d}\right)$. These guarantee that $\pi_{i}, i=1,2,3$ are well-defined continuous functions of $P$ and $T$.

\subsection{Case 2: $T_{d}>M$.}

We analyze three sub-cases as follows.

Sub-case 2.1: $M \leq T_{d} \leq T$. This scenario is same as sub-case 1.1. Therefore, the interest earned on the generated revenue during $[0, M]$ is $I E_{4}=I E_{1}=\frac{P I_{e}}{T} \int_{0}^{M} R(P) t d t=\frac{a P^{-\eta+1} I_{e} M^{2}}{2}$. During $[M, T]$, the retailer pays interest against unsold stock at the rate $I_{c}$ as $I C_{4}=I C_{1}=\frac{C I_{c}}{T} \int_{M}^{T} I(t) d t$ $=\frac{C I_{c} a P^{-\eta}}{4 T}\left[T^{2}-M^{2}-2(T-M)(1+m)+2 \ln \left(\frac{1+m-M}{1+m-T}\right)\left((M-1)^{2}+m^{2}-2 M m+2 m\right]\right.$.

Sub-case 2.2: $M \leq T \leq T_{d}$. Here, the retailer qualifies for partial credit period. .For partial cash-down payment, the interest charged, $I C_{5}=\frac{(1-\alpha) C I_{C}}{T} \int_{0}^{T} I(t) d t+\frac{\alpha C I_{C}}{T} \int_{0}^{M} I(t) d t$ and interest earned during $[0, M]$ is $I E_{2}=\frac{\alpha a P^{-\eta+1} I_{e} M^{2}}{2 T}$.

Sub-case 2.3: $T \leq M<T_{d}$. The retailer qualifies for partial trade credit. Then, the interest paid, $I C_{6}=I C_{3}=\frac{(1-\alpha) C I_{C}}{T} \int_{0}^{T} I(t) d t=\frac{(1-\alpha) C I_{C} a P^{-\eta}}{4 T}\left[T^{2}-2 T(1+m)+2 \ln \left(\frac{1+m}{1+m-T}\right)(1+m)^{2}\right] \quad$ and interest earned on the generated revenue, $I E_{6}=I E_{3}=\frac{\alpha a I_{e} P^{-\eta+1}(2 M-T)}{2}$.

The total profits per unit time for the retailer in three sub-cases when $T_{d}>M$ are given by

$$
\pi_{4}(P, T)=S R-P C-O C-H C+I E_{4}-I C_{4}, M \leq T_{d} \leq T
$$




$$
\begin{aligned}
& \pi_{5}(P, T)=S R-P C-O C-H C+I E_{5}-I C_{5}, M \leq T \leq T_{d} \\
& \pi_{6}(P, T)=S R-P C-O C-H C+I E_{6}-I C_{6}, T \leq M \leq T_{d}
\end{aligned}
$$

The objective functions in Eqs. (1-6) are highly non-linear in two variables $P$ and $T$. It will hinder us to get closed form solution. So, the retailer is advised to perform following steps to obtain optimal solution.

\subsection{Computational Procedure}

Step 1: Input values to the inventory parameters.

Step 2: From given value of $Q_{d}$, compute $T_{d}$ from $Q_{d}=a P^{-\eta}(1+m) \ln \left(\frac{1+m}{1+m-T_{d}}\right)$.

Step 3: If $T_{d} \leq M$, then solve $\frac{\partial \pi_{i}(P, T)}{\partial P}=0$ and $\frac{\partial \pi_{i}(P, T)}{\partial T}=0, i=1,2,3$.

If $T_{d} \leq M \leq T$ then $\pi_{1}(P, T)$ is maximum

Else if $T_{d} \leq T \leq M$ then $\pi_{2}(P, T)$ is maximum

Else $\pi_{3}(P, T)$ is maximum.

Step 4: If $T_{d}>M$, then solve $\frac{\partial \pi_{i}(P, T)}{\partial P}=0$ and $\frac{\partial \pi_{i}(P, T)}{\partial T}=0, i=4,5,6$.

If $M \leq T_{d} \leq T$ then $\pi_{4}(P, T)$ is maximum

Else if $M \leq T_{d} \leq T$ then $\pi_{5}(P, T)$ is maximum

Else $\pi_{6}(P, T)$ is maximum.

Step 5: Compute corresponding optimal purchase quantity.

Next, we explore development of the mathematical model and steps given in algorithm to find optimal decision for parametric values.

\section{Numerical examples}

Let $a=20,000$ units/year, $\eta=1.5, m=1$ year, $C=\$ 10 /$ unit, $h=\$ 2.8 /$ unit/year, $A=\$ 120 /$ order, $I_{e}=9 \% / \$ /$ year, $I_{c}=14 \% / \$ /$ year and $M=0.3$ years. In Table 1 , we vary $Q_{d}=\{20,50\}, \alpha=\{0.2,0.5\}$ and $A=\{120,100,80,60,40,20\}$ to compute best possible scenario which maximizes the total profit per unit time of the retailer. The concavity of the profit function is presented in fig.1. Also, the sufficiency condition satisfies the criteria of maximizing objective function as

$$
\left|\begin{array}{ll}
\frac{\partial^{2} \pi_{1}}{\partial T^{2}} & \frac{\partial^{2} \pi_{1}}{\partial T \partial P} \\
\frac{\partial^{2} \pi_{1}}{\partial P \partial T} & \frac{\partial^{2} \pi_{1}}{\partial P^{2}}
\end{array}\right|=\left|\begin{array}{cc}
-2807.3972 & 22.7246 \\
22.7246 & -1.3096
\end{array}\right|=3160.37>0 \text { and } \frac{\partial^{2} \pi_{1}}{\partial T^{2}}<0 \text { and } \frac{\partial^{2} \pi_{1}}{\partial P^{2}}<0 .
$$


Table 1

Optimal Solution for scenarios

\begin{tabular}{|c|c|c|c|c|c|c|c|}
\hline$Q_{d}$ & $\alpha$ & $A$ & Scenario & $\begin{array}{c}T^{*} \\
\text { (years) }\end{array}$ & $\underset{\text { (units) }}{Q^{*}}$ & $\begin{array}{l}P^{*} \\
(\$)\end{array}$ & $\begin{array}{l}\pi^{*} \\
(\$)\end{array}$ \\
\hline \multirow{12}{*}{20} & \multirow{6}{*}{0.2} & 120 & $T_{d} \leq M<T$ & 0.412 & 47.70 & 35.87 & 1980.80 \\
\hline & & 100 & $T_{d} \leq M<T$ & 0.409 & 43.98 & 35.14 & 2027.24 \\
\hline & & 80 & $M$ & 0.300 & 33.70 & 33.38 & 2072.13 \\
\hline & & 60 & $T_{d} \leq T \leq M$ & 0.306 & 34.32 & 33.48 & 2138.88 \\
\hline & & 40 & $T_{d}$ & 0.173 & 20.00 & 31.58 & 2197.00 \\
\hline & & 20 & $T<T_{d} \leq M$ & 0.188 & 18.00 & 21.30 & 2240.13 \\
\hline & \multirow{6}{*}{0.5} & 120 & $T_{d} \leq M<T$ & 0.412 & 47.70 & 35.87 & 1980.80 \\
\hline & & 100 & $T_{d} \leq M<T$ & 0.409 & 43.98 & 35.14 & 2027.24 \\
\hline & & 80 & $M$ & 0.300 & 33.70 & 33.38 & 2072.13 \\
\hline & & 60 & $T_{d} \leq T \leq M$ & 0.306 & 34.32 & 33.48 & 2138.88 \\
\hline & & 40 & $T<T_{d} \leq M$ & 0.260 & 28.98 & 33.31 & 2173.93 \\
\hline & & 20 & $M \leq T_{d} \leq T$ & 0.149 & 17.68 & 31.28 & 2314.54 \\
\hline \multirow[t]{12}{*}{50} & \multirow{6}{*}{0.2} & 120 & $M \leq T_{d} \leq T$ & 0.452 & 47.70 & 35.87 & 1980.80 \\
\hline & & 100 & $M \leq T_{d} \leq T$ & 0.409 & 43.98 & 35.14 & 2027.24 \\
\hline & & 80 & $M \leq T_{d} \leq T$ & 0.381 & 39.53 & 35.78 & 2023.91 \\
\hline & & 60 & $T \leq M<T_{d}$ & 0.328 & 35.02 & 34.73 & 2085.07 \\
\hline & & 40 & $T \leq M<T_{d}$ & 0.267 & 29.26 & 33.75 & 2152.26 \\
\hline & & 20 & $T \leq M<T_{d}$ & 0.188 & 21.30 & 32.53 & 2240.13 \\
\hline & \multirow{6}{*}{0.5} & 120 & $M \leq T_{d} \leq T$ & 0.452 & 47.70 & 35.87 & 1980.80 \\
\hline & & 100 & $M \leq T_{d} \leq T$ & 0.409 & 43.98 & 35.14 & 2027.24 \\
\hline & & 80 & $M \leq T_{d} \leq T$ & 0.372 & 38.95 & 35.50 & 2035.03 \\
\hline & & 60 & $M \leq T_{d} \leq T$ & 0.314 & 33.67 & 34.50 & 2093.34 \\
\hline & & 40 & $T \leq M<T_{d}$ & 0.260 & 28.98 & 33.31 & 2173.93 \\
\hline & & 20 & $T \leq M<T_{d}$ & 0.183 & 21.07 & 32.16 & 2264.18 \\
\hline
\end{tabular}

It is observed from Table 1, that for given pre-specified units and fraction of payment, selling price and purchase quantity decrease drastically with increase in ordering cost. If retailer does partial cash payment, he/she will save in interest charges to be paid and consequently increases total profit of the inventory system. If pre-specified order is increased to avail of full credit period, then cycle time and total profit per unit time of the inventory system increases. This is due to savings in the ordering cost. For fixed $Q_{d}$, increase in $\alpha$ decreases selling price when ordering cost decreases. It also suggests the decision maker which scenario is advantageous. 


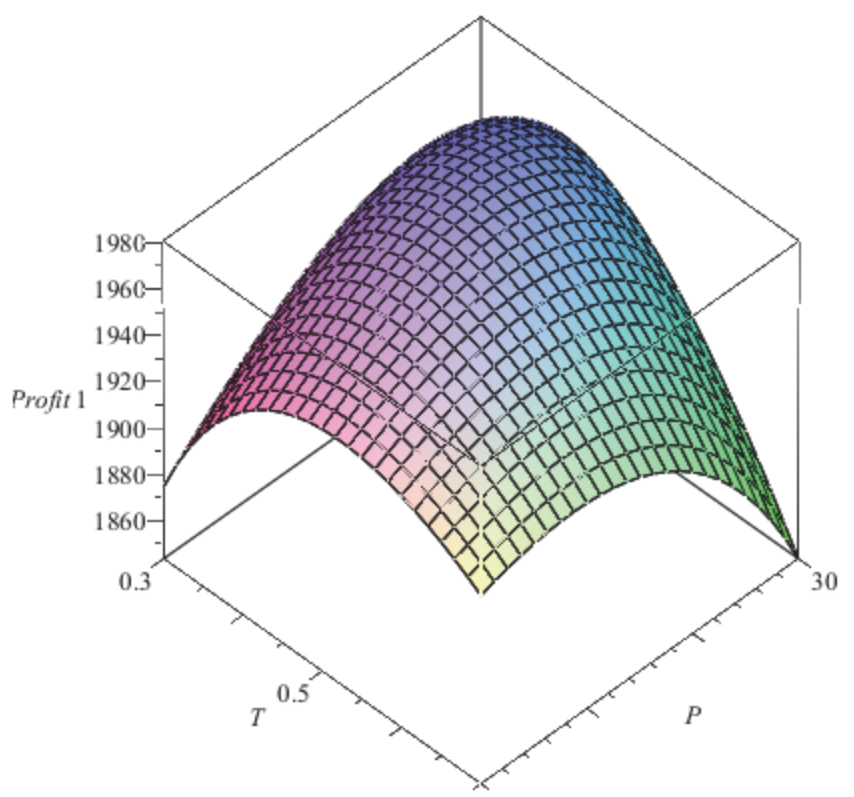

Fig. 1. Concavity of Profit function

\section{Conclusion}

In this paper, in contrast to Chen et al. (2014), selling price has been considered to be a decision variable. The effect of time-varying deterioration on the decision variables and objective function has been studied when product has a fixed lifetime. Theoretical results have been explored using numerical data to obtain some managerial issues for the retailer.

For future research, one can consider different types of demands, in particular stochastic and fuzzy demand. The integrated system is also worth analyzed using game theory approach.

\section{Acknowledgement}

Author thanks anonymous reviewer for the constructive comments. The author thanks DST-FIST file \# MSI-097 for support to the department of Mathematics.

\section{References}

Chang, C. T., Ouyang, L. Y. \& Teng, J.T. (2013). An EOQ model for deteriorating items under supplier credits linked to order quantity. Applied Mathematical Modelling, 27(12), 983 - 996.

Chang, C. T., Teng, J. T. \& Goyal, S. K. (2008). Inventory lot-size models under trade credit: A review. Asia-Pacific Journal of Operational Research, 25 (1), 89 - 112.

Chang, C. T., Teng, J. T. \& Chern, M. S. (2010). Optimal manufacturer's replenishment policies for deteriorating items in a supply chain with up-stream and down-stream trade credits. International Journal of Production Economics, 127 (1), 197 - 202.

Cheng, M. C., Chang, C. T. \& Ouyang, L. Y. (2012). The retailer's optimal ordering policy with trade credit in different financial environments. Applied Mathematics and Computation, 218 (19), 9623 9634.

Chen, S. C., Léopold, E. C.-B. \& Teng, J. T. (2014). Retailer's economic order quantity when the supplier offers conditionally permissible delay in payments link to order quantity. International Journal of Production Economics, 155 (1), 284 - 291.

Goyal, S. K. (1985). Economic order quantity under conditions of permissible delay in payments. Journal of the Operational Research Society, 36 (4), 335 - 338. 
Goyal, S. K., Teng, J. T. \& Chang, C. T. (2007). Optimal ordering policies when the supplier provides a progressive interest - payable scheme. European Journal of Operational Research, 179 (2), 404 $-413$.

Huang, Y. F. \& Hsu, K. H. (2008). An EOQ model under retailer partial trade credit policy in supply chain. International Journal of Production Economics, 112 (2), 655 - 664.

Hwang, H., Shinn, S. W. (1997). Retailer's pricing and lot sizing policy for exponentially deteriorating products under the condition of permissible delay in payments. Computers and Operations Research, 24 (6), $539-547$.

Jamal, A. M. M., Sarker, B. R. \& Wang, S. (1997). An ordering policy for deteriorating items with allowable shortage and permissible delay in payment. Journal of the Operational Research Society, $48(1), 826-833$.

Kreng, V. B., Tan, S. J. (2010). The optimal replenishment decisions under two levels of trade credit policy depending on the order quantity. Expert Systems with Applications, 37 (7), $5514-5522$.

Kreng, V. B., Tan, S. J. (2011). Optimal replenishment decision in an EPQ model with defective items under supply chain trade credit policy. Expert Systems with Applications, 38 (8), 9888 - 9899.

Liao, J. J. (2008). An EOQ model with non-instantaneous receipt and exponentially deteriorating items under two-level trade credit. International Journal of Production Economics, 113 (2), 852 - 861.

Molamohamadi, Z., Ismail, N., Leman, Z. \& Zulkifli, N. (2014). Reviewing the literature of inventory models under trade credit contract. Discrete, Dynamic in Nature and Society, 2014, Article ID 975424, 19 pages.

Ouyang, L. Y., Chang, C. T. \& Teng, J. T. (2005). An EOQ model for deteriorating items under trade credits. Journal of the Operational Research Society, 56 (6), 719 - 726.

Ouyang, L. Y., Teng, J. T. \& Chen, L. H. (2006). Optimal ordering policy for deteriorating items with partial backlogging under permissible delay in payments. Journal of Global Optimization, 34 (2), $245-271$.

Shah, N. H. (1993). Probabilistic time-scheduling model for an exponentially decaying inventory when delay in payment is permissible. International Journal of Production Economics, 32 (1), 77 - 82.

Shah, N. H., Soni, H. \& Jaggi, C. K. (2010). Inventory modeling and trade credit: A review. Control and Cybernetics, 39 (3), $867-882$.

Shinn, S. W., Hwang, H. (2003). Optimal pricing and ordering policies for retailers under order-size dependent delay in payments. Computers and Operations Research, 30 (1), 35 - 50.

Soni, H., Shah, N. H. (2008). Optimal ordering policy for stock-dependent demand under progressive payment scheme. European Journal of Operational Research, 184 (1), 91 -100.

Teng, J. T. (2002). On the economic order quantity under conditions of permissible delay in payments. Journal of the Operational Research Society, 53 (8), 915 - 918.

Teng, J. T., Krommyda, I. P., Skouri, K. \& Lou, K. R. (2011). A comprehensive extension of optimal ordering policy for stock-dependent demand under progressive payment scheme. European Journal of Operational Research, 215 (1), 97 - 104.

Teng, J. T. \& Lou, K. R. (2012). Seller's optimal credit period and replenishment time in a supply chain with up-stream and down-stream trade credits. Journal of Global Optimization, 53 (3), 417 - 430.



(C) 2016 by the authors; licensee Growing Science, Canada. This is an open access article distributed under the terms and conditions of the Creative Commons Attribution (CC-BY) license (http://creativecommons.org/licenses/by/4.0/). 